\title{
(6) OPEN ACCESS \\ Athletic groin pain (part 2): a prospective cohort study on the biomechanical evaluation of change of direction identifies three clusters of movement patterns
}

\author{
A Franklyn-Miller, ${ }^{1,2}$ C Richter, ${ }^{1}$ E King, ${ }^{1,3}$ S Gore, ${ }^{1,4}$ K Moran, ${ }^{4,5}$ S Strike, ${ }^{3}$ \\ E C Falvey ${ }^{1,6}$
}

- Additional material is published online only. To view please visit the journal online (http://dx.doi.org/10.1136/ bjsports-2016-096050)

'Sports Medicine Research Department, Sports Surgery Clinic, Santry Demesne, Dublin, Ireland

${ }^{2}$ Centre for Health, Exercise and Sports Medicine, University of Melbourne, Melbourne, Victoria, Australia

${ }^{3}$ Department of Life Sciences, Roehampton University,

London, UK

${ }^{4}$ INSIGHT Research Centre Dublin City University, Dublin, Ireland

${ }^{5} 5$ chool of Health and Human Performance, Dublin City University, Dublin, Ireland ${ }^{6}$ Department of Medicine, University College Cork, Cork, Ireland

Correspondence to Dr A Franklyn-Miller; afranklynmiller@me.com

Accepted 8 September 2016 Published Online First 6 October 2016

CrossMark

To cite: Franklyn-Miller A, Richter C, King E, et al. Br J Sports Med 2017:51:460-468

\section{ABSTRACT}

Background Athletic groin pain (AGP) is prevalent in sports involving repeated accelerations, decelerations, kicking and change-of-direction movements. Clinical and radiological examinations lack the ability to assess pathomechanics of AGP, but three-dimensional biomechanical movement analysis may be an important innovation.

Aim The primary aim was to describe and analyse movements used by patients with AGP during a maximum effort change-of-direction task. The secondary aim was to determine if specific anatomical diagnoses were related to a distinct movement strategy.

Methods 322 athletes with a current symptom of chronic AGP participated. Structured and standardised clinical assessments and radiological examinations were performed on all participants. Additionally, each participant performed multiple repetitions of a planned maximum effort change-of-direction task during which whole body kinematics were recorded. Kinematic and kinetic data were examined using continuous waveform analysis techniques in combination with a subgroup design that used gap statistic and hierarchical clustering. Results Three subgroups (clusters) were identified. Kinematic and kinetic measures of the clusters differed strongly in patterns observed in thorax, pelvis, hip, knee and ankle. Cluster 1 (40\%) was characterised by increased ankle eversion, external rotation and knee internal rotation and greater knee work. Cluster 2 (15\%) was characterised by increased hip flexion, pelvis contralateral drop, thorax tilt and increased hip work. Cluster 3 (45\%) was characterised by high ankle dorsiflexion, thorax contralateral drop, ankle work and prolonged ground contact time. No correlation was observed between movement clusters and clinically palpated location of the participant's pain.

Conclusions We identified three distinct movement strategies among athletes with long-standing groin pain during a maximum effort change-of-direction task These movement strategies were not related to clinical assessment findings but highlighted targets for rehabilitation in response to possible propagative mechanisms.

Trial registration number NCT02437942, pre results.

\section{INTRODUCTION}

Athletic groin pain (AGP) is a common chronic presentation in professional and amateur sport. ${ }^{12}$ A recent systematic review in football ${ }^{2}$ reported an incidence of AGP between 0.2 and 2.1/1000 hour in men; hip/groin injuries were the third most common injuries (14\%). Similar incidences rates are reported in field sports such as Rugby Union, ${ }^{34}$ Australian Rules Football ${ }^{5}$ and Gaelic football ${ }^{6} 7$ which share the common requirement of acceleration, deceleration, kicking and 'cutting' (movements combining deceleration and acceleration with a change of direction).

Research into AGP to date has focused on trying to localise the 'injured' or 'painful' structure clinically, ${ }^{8-10}$ radiologically ${ }^{11-13}$ and surgically. ${ }^{14-18}$ Existing clinical examination of patients with AGP has been largely confined to palpation for pain, ${ }^{19-21}$ range of motion ${ }^{20}$ and dynamometer-based strength testing in a single plane. ${ }^{22} 23$ Biomechanical segmental coordination (as described by the relationships between segments articulating at the hip, knee and ankle joints) during movements has not been considered.

Segmental coordination is intrinsic to an athlete's ability to control change of direction and produce power to execute movement. ${ }^{24}{ }^{25} \mathrm{~A}$ loss of segmental coordination may lead to tissue injury, if the magnitude, rate and direction of the loading of muscles around a joint or joints exceeds that of tissue tolerance. ${ }^{26}$ This coordination can be examined using a three-dimensional motion analysis system. Three-dimensional motion analysis systems have successfully identified pathomechanics of anterior cruciate ligament injuries ${ }^{27}$ and might also help explain causes of painful structures encountered in AGP. Therefore, studying the movement strategies during a multidirectional movement task might reveal potential injury mechanisms.

Our primary aim was to describe and analyse the movement pattern used by patients with AGP during a planned maximum effort change-of-direction task. Our secondary aim was to determine if specific anatomical diagnoses related to a distinct movement pattern.

\section{METHODS}

\section{Participants}

In total, 382 consecutive male participants presenting with chronic AGP were recruited. All players were experienced multidirectional field athletes. The Sports Surgery Clinic Hospital Ethics Committee approved the study (Ref 25EF011) and all participants signed informed consent. The study was registered at Clinicaltrials.gov (NCT02437942). 


\section{Clinical examination}

A detailed history, clinical examination, ${ }^{10} \mathrm{Hip}$ and Groin Outcome Score ${ }^{28}$ and magnetic resonance pelvis imaging was carried out on each participant, the methodology and results of which are reported previously. ${ }^{29}$ This combined assessment, resulted in an anatomical clinical diagnosis for each participant.

\section{Biomechanical examination}

Participants undertook a standardised warm-up (five body weight squats and five submaximal countermovement jumps). ${ }^{30}$ The multidirectional test protocol involved three maximal effort trials (left and right limb turning) of a planned $110^{\circ}$ cutting manoeuvre (figure 1A). ${ }^{31}$ The order of which turn to use first was randomised. Instructions given were as follows: run as fast as possible towards the cone (red triangle; figure 1A), make a single complete foot contact in front of the cone and run maximally to the finish line and plant with the outside foot (when cutting left, plant with the right and vice versa). Each participant undertook two submaximal practice trials of the cut before test trials were captured. A 1-min recovery was taken between trials.

\section{Data acquisition and analysis}

An eight-camera motion analysis system (Bonita-B10, Vicon Motion Systems, UK), synchronised with two force platforms (BP400600, AMTI, USA), was used to record 24 reflective markers (1.4 cm diameter) and ground reaction forces (GRFs). Reflective markers were secured using tape, at bony landmarks on the lower limbs, pelvis ${ }^{32}$ and trunk (modified Plug-in-Gait marker set to include the trunk) (figure 1B). A software package (Nexus 1.8.5, Vicon Motion Systems, UK) controlled simultaneous collection of motion and force data $(200 \mathrm{~Hz}, 1000 \mathrm{~Hz})$, which were filtered using a fourth-order low-pass Butterworth filter (cut-off frequency of $15 \mathrm{~Hz}^{33}$ ). Standard inverse dynamics analysis was used to calculate tri-planar external joint moments. ${ }^{34}$ The start and end of the test (cutting) movement was defined by the GRF $(>5 \mathrm{~N})$. Curves were normalised to 101 frames and landmark registered ${ }^{35}$ to the start of the acceleration phase (last positive anterior GRF before negative peak; at 46\% of the movement cycle) (figure 2). This process aligned the start of the acceleration phase (47\%) for every participant, and it accounts for differences in braking/deceleration and acceleration phase across the participant during a continuous waveform analysis.

Joint work was calculated as the sum of the moment (m) multiplied with the change in angle $(\sigma)$ of all three planes ( $\mathrm{p}$; flexion, adduction, internal rotation) for every time point $(\mathrm{t})$ over the cycle for each joint ( $\mathrm{j}$ : ankle, knee and hip), generating a single measure for joint work (equations (1) and (2)).

$$
\text { work }_{\mathrm{j}}=\text { work }_{\mathrm{j}, \text { flex }}+\text { work }_{\mathrm{j}, \text { abd }}+\text { work }_{\mathrm{j}, \text { rot }}
$$

Where

$$
\operatorname{work}_{\mathrm{j}, \mathrm{p}}=\sum_{\mathrm{t}=1}^{101}{\sqrt{\left(\mathrm{m}_{\mathrm{j}, \mathrm{p}}(\mathrm{t}) \times\left(\sigma_{\mathrm{j}, \mathrm{p}}(\mathrm{t})-\sigma_{\mathrm{j}, \mathrm{p}}(\mathrm{t}-1)\right)\right)^{2}}}^{2}
$$

As calculated, joint work refers to the amount of work done by all muscles acting across a joint.

\section{Clustering}

The data were examined for subgroups (clusters), using kinematic (ankle, knee, hip, pelvis and thorax angles) and kinetic variables (ankle, knee and hip moments) using only the painful side (by clinical palpation) for analysis. Where pain was found on both sides, we randomly selected the left or right side. Where no palpation pain was identified, the side of MRI confirmed pathology (eg, hip injury or aponeurosis injury) was used. Again, where both sides were affected, we randomly selected the left or right side.

For the clustering process, analysis of characterising phases was used to calculate subject scores that describe the behaviour of each participant within phases of variation of the selected variables, which were combined into a matrix (number phases of variation $\times$ number participant) and normalised for further processing. ${ }^{36}$ The normalisation was performed by transforming the combined similarity scores into their correlation matrix, to quantify numerically the relationship between the behaviour of participant, which cannot be described by distances of the generated similarity scores. ${ }^{37}$ Subsequently, gap statistic was used to decide number of clusters $(\mathrm{k})$ within the sample. ${ }^{38}$ Gap statistics compare the within-cluster dispersion of a data set for a number of requested cluster solution (eg, $\mathrm{k}=2$ to 25 ) to the average within-cluster dispersion. Following this differentiation of the number of clusters, the correlation matrix was used as input for a hierarchical clustering approach (figure 3).

Gap statistics suggested examining our data based on a 3 cluster solution, henceforth referred to as cluster 1, 2 and 3. A full and detailed description of this methodology is available as online supplementary appendix A.

\section{Statistical analysis}

To identify differences in kinematic and kinetic measures between the clusters, statistical parametric mapping was used. ${ }^{39} 40$ The Cohen's D effect size was calculated in a point-by-point manner to determine clinical relevance of a difference $\left(\mathrm{d}>0.5=\right.$ medium; $\mathrm{d}>0.7=$ strong). ${ }^{41}$ Significant differences with a Cohen's $\mathrm{D}<0.5$ were discarded. For the discrete work measures, an analysis of variance (ANOVA) was used to identify differences between the clusters, and a post hoc test was performed if significant differences were found. To compare the interrelation between the identified clusters and the clinical diagnoses, a contingency table (cross tabulation) was used. The significance of this relationship was assessed using Pearson's $\chi^{2}$ test. All data processing and statistical analyses were performed using MATLAB (R2015a, MathWorks, USA).

\section{RESULTS}

Participants were aged $27.6( \pm 7.6)$ years old, $180( \pm 6.0) \mathrm{cm}$ tall and $81.9( \pm 9.4) \mathrm{kg}$ with a median time of 36 (IQR 16-75) weeks between onset of symptoms and presentation. From 382 original participants, 322 participants were used for the analysis. A total of 31 participants had missing motion analysis data (they did not attend the motion analysis appointment). While all remaining participants were able to perform the cutting task, 29 had partial or double leg force plate contacts and had to be excluded from further analysis.

Three distinct movement strategies (clusters) were identified with differences in braking and acceleration phases by joint and plane of movement kinematics (table 1 and figure 4A-E) and kinetics by joint and plane (table 2 and figure 5A-E).

Each cluster is pictorially represented in sagittal (figure 6) and frontal (figure 7) plane highlighting gross differences, and in comparison of moment and total work done by the joints (figure 8)-all descriptions of differences are in comparison to the other clusters. A detailed description of findings can be found in table 1 and 2. 
Figure $1 \quad A, B$ Illustration of the multidirectional movement task and a schematic illustration of the landmarks of the marker setup.

A

B

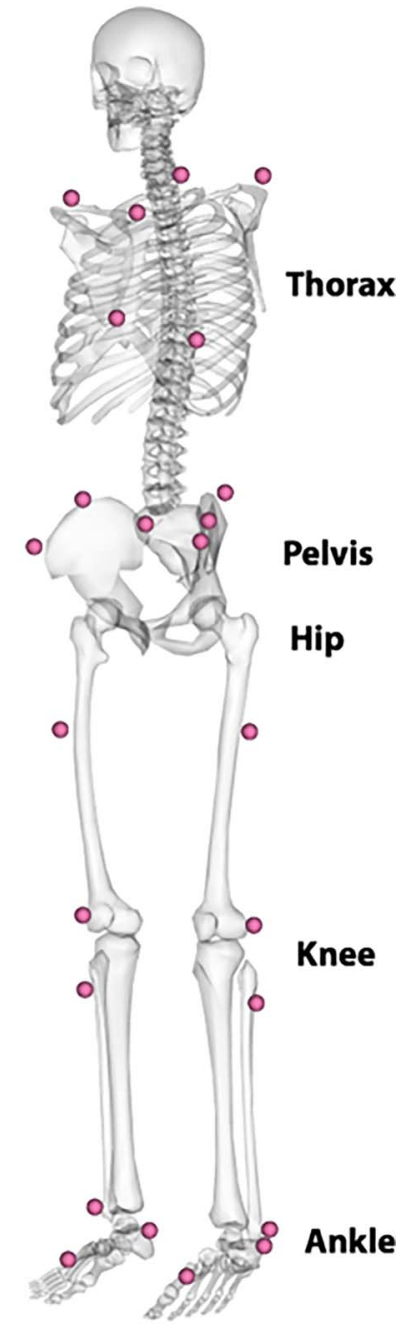

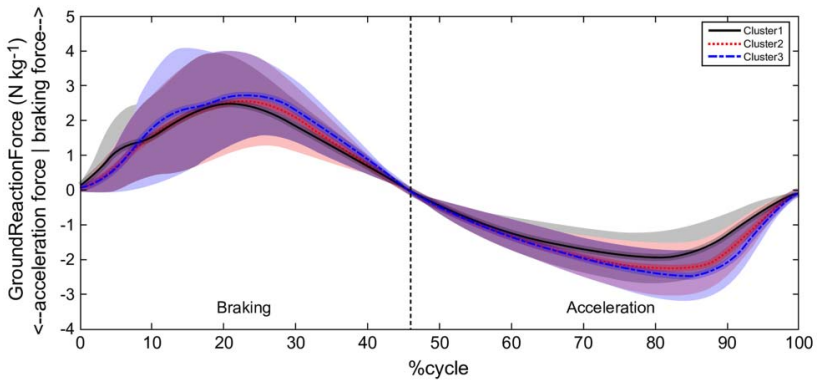

Figure 2 Illustration of the mean and SD of the raw and landmarked ground reaction force curve.

\section{Cluster 1}

Cluster 1 represents $40 \%(n=128)$ of the cohort, and the main cluster features are increased ankle eversion, external rotation and knee internal rotation (table 1) throughout the braking and acceleration phase. In addition, cluster 1 demonstrated a high degree of hip internal rotation (figure 4B). The thorax segment demonstrates the smallest anterior tilt and medium ipsilateral drop throughout the braking phase, while it features late turning rotation towards the direction of travel in the acceleration phase (figure 4E) (table 1).

These kinematic features map with the kinetic differences (table 2, figures 5 and 8) seen with cluster 1 demonstrating the highest proportion of work done at the knee (effect size 0.72-0.92).

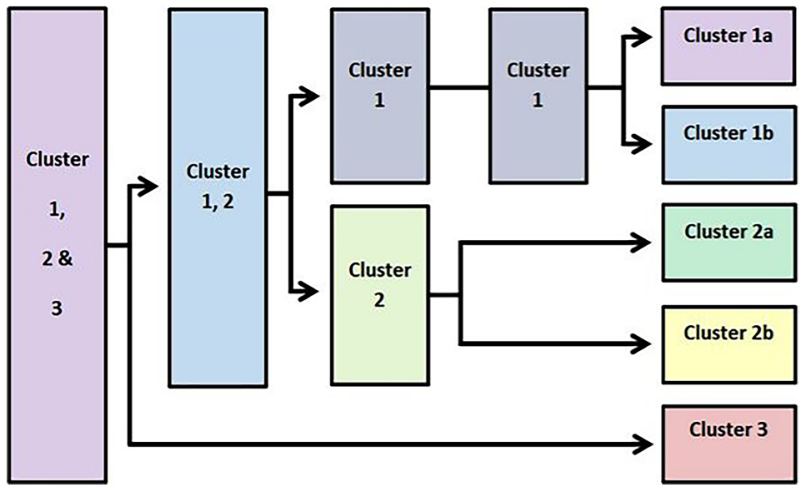

Figure 3 Representation of the splitting behaviour of the sample for increasing number of clusters.

\section{Cluster 2}

Cluster 2 represents 19\% $(n=62)$ of the cohort and is differentiated from cluster 1 and 3, predominantly by greater degrees of hip flexion (effect size $0.86-1.41$ ) throughout braking and acceleration (table 1). At the pelvis, we observed an increased anterior tilt (figure 4E) as well as decreased contralateral drop and ipsilateral rotation throughout the cycle. At the thorax, cluster 2 demonstrated an increased anterior tilt and ipsilateral drop (figure 4F). Again this maps well with kinetics demonstrating the highest proportion of work done at the hip (table 2, figures 5 and 8). 
Table 1 Description of kinematic differences between clusters 1, 2 and 3 with strong effect sizes

\begin{tabular}{|c|c|c|c|c|c|}
\hline Joint & Findings & Detailed & Phase & $\begin{array}{l}\text { Mean } \\
\text { difference }\end{array}$ & Effect \\
\hline \multicolumn{6}{|l|}{ Kinematics } \\
\hline \multicolumn{6}{|l|}{ Ankle } \\
\hline \multirow[t]{2}{*}{ Dorsiflexion (+) } & $1,3>2$ & $1>2$ & $24-63 \%$ & 4.44 & 0.56 \\
\hline & & $3>2$ & $8-64 \%$ & 6.77 & 0.76 \\
\hline \multirow[t]{2}{*}{ Eversion (+) } & $1>2,3$ & $1>2$ & $1-100 \%$ & 2.25 & 1.13 \\
\hline & & $1>3$ & $1-100 \%$ & 1.87 & 0.86 \\
\hline \multirow[t]{2}{*}{ External rot. (-) } & $1>2,3$ & $1>2$ & $1-100 \%$ & 15.73 & 1.27 \\
\hline & & $1>3$ & $1-100 \%$ & 13.66 & 1.06 \\
\hline \multicolumn{6}{|l|}{ Knee } \\
\hline \multirow[t]{2}{*}{ Flexion (+) } & $1,2>3$ & $1>3$ & $12-88 \%$ & 9.06 & 0.90 \\
\hline & & $2>3$ & $17-90 \%$ & 8.36 & 0.81 \\
\hline \multirow[t]{2}{*}{ Valgus (-) } & $1,2>3$ & $1>3$ & $7-12 \%$ & 3.70 & 0.55 \\
\hline & & $2>3$ & $87-95 \%$ & 2.95 & 0.51 \\
\hline \multirow[t]{2}{*}{ Internal rot. (+) } & $1>2,3$ & $1>2$ & $1-100 \%$ & 11.64 & 1.11 \\
\hline & & $1>3$ & $1-100 \%$ & 13.64 & 1.14 \\
\hline \multicolumn{6}{|l|}{ Hip } \\
\hline \multirow[t]{3}{*}{ Flexion (+) } & $2>1>3$ & $2>1$ & $1-100 \%$ & 8.29 & 0.86 \\
\hline & & $2>3$ & $1-100 \%$ & 17.67 & 1.36 \\
\hline & & $1>3$ & $1-100 \%$ & 10.13 & 0.96 \\
\hline \multirow[t]{2}{*}{ Abduction (-) } & $1,2>3$ & $1>3$ & $79-100 \%$ & 4.03 & 0.66 \\
\hline & & $2>3$ & $76-100 \%$ & 5.15 & 0.77 \\
\hline \multirow[t]{2}{*}{ Internal rot. (+) } & $1,2>3$ & $1>2$ & $48-64 \%$ & 6.64 & 0.55 \\
\hline & & $2>3$ & $32-75 \%$ & 7.81 & 0.64 \\
\hline \multicolumn{6}{|l|}{ Pelvis } \\
\hline \multirow[t]{2}{*}{ Anterior tilt (+) } & $2>1,3$ & $2>1$ & $44-69 \%$ & 3.72 & 0.52 \\
\hline & & $2>3$ & $29-100 \%$ & 4.56 & 0.63 \\
\hline \multirow[t]{3}{*}{ Contralateral drop (+) } & $3>1>2$ & $3>1$ & $1-100 \%$ & 4.95 & 0.82 \\
\hline & & $3>2$ & $1-100 \%$ & 6.99 & 1.01 \\
\hline & & $1>2$ & $29-38 \%$ & 2.99 & 0.51 \\
\hline \multirow[t]{3}{*}{ Ipsilateral rot. (-) } & $2>1>3$ & $2>1$ & $21-89 \%$ & 6.38 & 0.58 \\
\hline & & $2>3$ & $1-100 \%$ & 13.31 & 1.10 \\
\hline & & $1>3$ & $1-100 \%$ & 7.68 & 0.73 \\
\hline \multicolumn{6}{|l|}{ Thorax } \\
\hline \multirow[t]{2}{*}{ Anterior tilt (+) } & $2>1,3$ & $2>1$ & $1-100 \%$ & 8.92 & 0.72 \\
\hline & & $2>3$ & $48-100 \%$ & 7.36 & 0.56 \\
\hline \multirow[t]{3}{*}{ Ipsilateral drop (-) } & $2>1>3$ & $2>1$ & $1-89 \%$ & 6.73 & 0.75 \\
\hline & & $2>3$ & $1-100 \%$ & 14.02 & 1.21 \\
\hline & & $1>3$ & $1-100 \%$ & 7.57 & 0.79 \\
\hline \multirow[t]{3}{*}{ Ipsilateral rot. (-) } & $1,2>3$ & $1>3$ & $1-73 \%$ & 5.92 & 0.61 \\
\hline & & $2>3$ & $1-100 \%$ & 9.28 & 0.90 \\
\hline & $2>1$ & $2>1$ & $95-100 \%$ & 5.71 & 0.54 \\
\hline \multicolumn{6}{|l|}{ Temporal } \\
\hline \multicolumn{6}{|l|}{ Time } \\
\hline Ground contact time & $1,2>3$ & $1>3$ & - & 0.04 & 0.85 \\
\hline & & $2>3$ & - & 0.05 & 0.93 \\
\hline
\end{tabular}

Mean values and effect sizes are calculated over the phase of significant difference. Rot, rotation.

\section{Cluster 3}

Cluster 3 represents $41 \%(n=132)$ of the cohort and was characterised by reduced hip and knee flexion as well as increased contralateral pelvis drop (table 1). In addition, cluster 3 demonstrated a decreased knee valgus, internal rotation of the hip, less hip extension and greater hip adduction in the acceleration phase than the other clusters. We further observed an increased contralateral pelvis rotation. The thorax demonstrated increased contralateral drop (during the acceleration phase) and rotation towards the direction of travel (contralateral rotation) (table 1). Cluster 3 featured the predominant work done at the ankle with plantarflexor and evertor moments greater in the first part of the cycle but smaller in the latter part 75-100\% (table 2 and figures 5 and 8).

\section{Clinical diagnoses}

Participants were classified into one or more of the five anatomical diagnoses, based on previous clinical and MRI examination (table 3). ${ }^{29}$ A primary clinical diagnosis of pubic aponeurosis injury was made in 194 (61\%) cases (Dx aponeurosis); hip injury was diagnosed in $63(20 \%)$ cases (Dx hip)-these overlapped in $8(2 \%)$ cases (Dx aponeurosis and Dx hip). Eight patients $(2 \%)$ were referred for arthroscopic hip evaluation (Dx hipflex). Adductor injury was diagnosed in 45 (14\%) cases (Dx adductor), and inguinal injury in $2(1 \%)$ cases (all related to the ilioinguinal nerve; Dx inguinal). The diagnosis Dx aponeurosis and Dx adductor and Dx aponeurosis and Dx hipflex was made each in one case. These are explored in detail in a complementary paper. $^{29}$ No significant relationship $(p>0.644)$ exists between movement cluster and the anatomical diagnoses. The most common anatomical diagnosis of aponeurosis injury was evenly distributed between movement clusters (table 3).

\section{DISCUSSION}

This is the first study to examine movement patterns in participants with AGP during a change-of-direction task. While performing a planned maximum effort change-of-direction task, participants with a current symptom of AGP could be characterised as using one of three distinct movement strategies. These strategies may represent different mechanisms of distributing the resultant load, between segments that is, a thorax, hip, knee or ankle dominant strategy that could lead to tissue overload and propagation of AGP or may be compensatory due to the injured structure being unable to tolerate that load or the pattern of neuromuscular control altered. ${ }^{42}$

\section{Underlying mechanism}

Hip joint

Data are not available to relate kinematic measures to the resulting hip joint force for change-of-direction tasks; however, any change in hip flexion angle will alter muscular action ${ }^{43}$ and ultimately the resultant hip joint force. ${ }^{44}{ }^{45}$ Hip flexion differed strongly between clusters over the whole movement cycle (cluster $2>1>3$ ), with a mean difference of $17^{\circ}$ between cluster 2 and 3. During hip flexion, the vector of the resultant joint force fluctuates. ${ }^{46}$ This implies large differences in anterior hip joint forces between the clusters. In particular, high shear forces might present a risk in overloading stabilising muscle, as the cartilaginous surface of hip is designed to primarily tolerate compressive load. ${ }^{47}$ This was previously demonstrated during walking where Lewis $e t a l^{45}$ reported significant changes (24\%) in anterior hip joint force (forces through the acetabulum and anterior pubic ramus) with only a $2^{\circ}$ reduction in hip extension angle. The different hip flexion angles found among clusters are likely to alter the hip shear force and suggest differing sites of load.

\section{Proximal segments}

The thorax segment demonstrated large differences in all three planes between the clusters. The thorax accounts for upwards of $35 \%$ of body mass, ${ }^{34}$ its position is influenced by pelvis orientation and controlled in part by the abdominal muscles (internal and external obliques, rectus abdominis and 
A

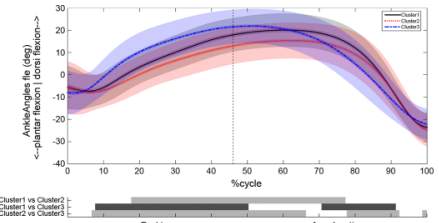

B

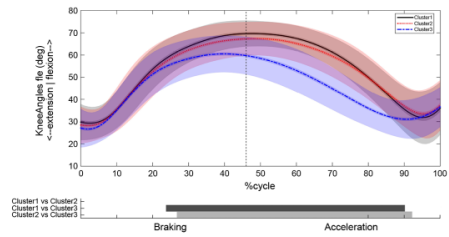

C

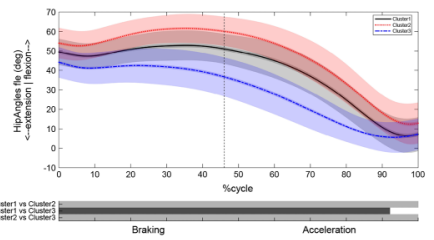

D

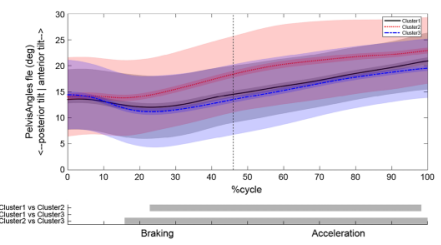

$E$

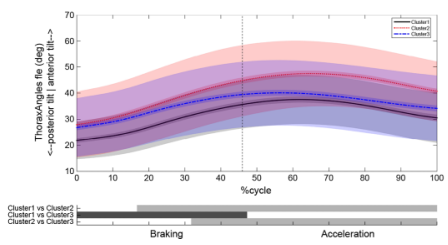

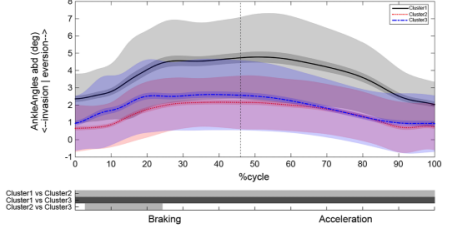
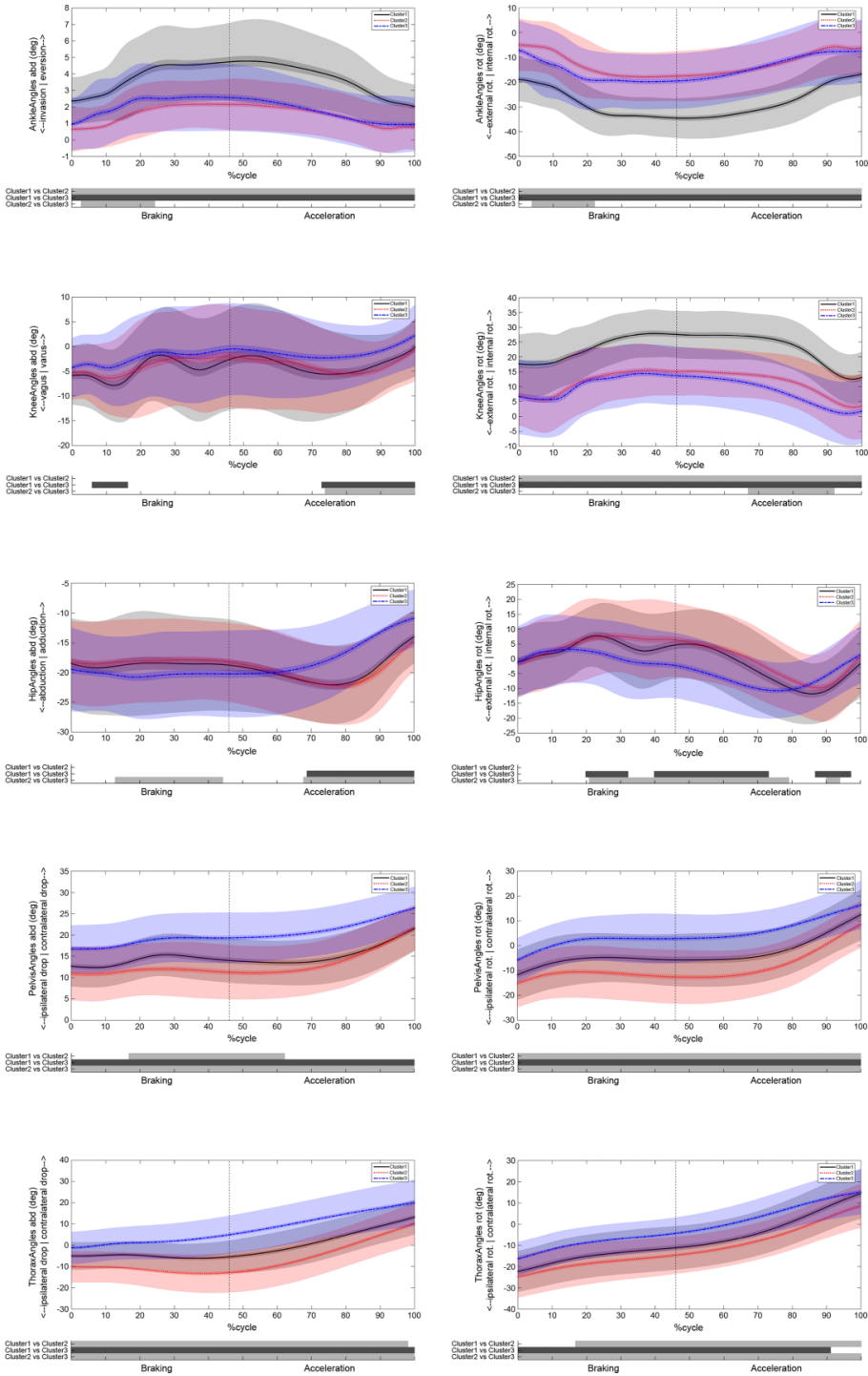

Figure 4 Graphical representations of joint kinematics in each plane. Black continuous line represents cluster 1, red dotted line cluster 2 and blue broken line cluster 3. Below each graph, the shaded bars represent significant differences between clusters. Where (A) represents ankle, (B) represents knee, (C) represents hip, (D) represents pelvis and (E) represents thorax.

transversus abdominis), which form the inguinal ligament superiorly and join the tendinous fascia of the common adductors inferiorly to form an aponeurosis at the pubic symphysis. ${ }^{48}$ In our cohort, we identified this as the primary site of pain in $>60 \%$ of cases.

Greater thorax anterior tilt (cluster 2) has been associated with greater adductor longus activation ${ }^{49}$ and greater activation of the hip extensors. To date, no relationship has been demonstrated between thorax angles and hip or groin injury; however, studies have demonstrated an association between thorax angles and knee injury. ${ }^{50}{ }^{51}$ We observed significant differences in magnitude and orientation of thorax and pelvis angles in the sagittal plane between the clusters, demonstrating an independent behaviour between thorax and pelvis where pelvic sagittal tilt is independent of torso movement. This differs from Houck et $a l,{ }^{52}$ who reported that thorax and pelvis could be considered as one segment-our findings indicate the opposite.

The relationship between interdependent body segments, with respect to joint position and segmental work, is known as dynamic coupling ${ }^{53}$ or intersegmental linkage, ${ }^{54}$ and as such, the influence of the position of the thorax ${ }^{55-58}$ must be considered in analysis of pelvic and lower limb biomechanics. The pubic symphysis can be thought of as the pivot or fulcrum around which many of these forces are exerted ${ }^{59}$ and pain in the pubic symphysis and rami is a common clinical sign in AGP.

Our cohort demonstrated different movement strategies between thorax and pelvis (figure 4E). The range of variation in these relationships could alter how the force is transmitted to the pubic bone by the displacement of centre of mass from centre of pressure, which alters the distribution of load by joint to differ. Increases in shear and compressive loading at the pubic symphysis, rectus abdominis and adductor attachments could also change the relationship between risk of injury to on-field training load. We propose that such a change in loading leads directly to the pubic bone oedema often seen on MRI imaging in this condition ${ }^{60}$ referred to incorrectly as osteitis pubis. ${ }^{6}$ It follows that a degree of bone oedema occurs in asymptomatic athletes by a similar mechanism of multidirectional loading ${ }^{13}{ }^{2}$ and has been demonstrated not to resolve post-surgery for AGP. ${ }^{63} 64$ 
Table 2 Descriptive of kinetic differences between the cluster 1, 2 and 3

\begin{tabular}{|c|c|c|c|c|c|}
\hline Measure & Findings & Detailed & Phase & $\begin{array}{l}\text { Mean } \\
\text { difference }\end{array}$ & Effect \\
\hline \multicolumn{6}{|l|}{ Kinetics } \\
\hline \multicolumn{6}{|l|}{ GRF } \\
\hline \multirow[t]{3}{*}{$\mathrm{x}$} & $1,2>3$ & $1>3$ & $10-30 \%$ & 0.73 & 0.56 \\
\hline & & $2>3$ & $12-22 \%$ & 0.82 & 0.52 \\
\hline & $3>2$ & $3>2$ & $91-98 \%$ & 0.25 & 0.53 \\
\hline \multirow[t]{3}{*}{ Y } & $3>1,2$ & $3>1$ & $43-56 \%$ & 1.29 & 0.54 \\
\hline & & $3>2$ & $31-66 \%$ & 1.87 & 0.77 \\
\hline & $2>3$ & $2>3$ & $84-92 \%$ & 0.99 & 0.53 \\
\hline \multirow[t]{3}{*}{ Z } & $3>2$ & $3>2$ & $38-60 \%$ & 1.98 & 0.68 \\
\hline & $1,2>3$ & $1>3$ & $76-93 \%$ & 1.66 & 0.56 \\
\hline & & $2>3$ & $79-97 \%$ & 1.56 & 0.64 \\
\hline \multicolumn{6}{|l|}{ Ankle } \\
\hline \multirow[t]{2}{*}{ Plantar moment (+) } & $1,3>2$ & $1>2$ & $10-75 \%$ & 5.10 & 0.71 \\
\hline & & $3>2$ & $14-64 \%$ * & 4.53 & 0.57 \\
\hline \multirow[t]{2}{*}{ Plantar moment $(+)$} & $1,2>3$ & $1>3$ & $79-87 \%$ & 4.26 & 0.52 \\
\hline & & $2>3$ & $86-100 \%$ & 2.63 & 0.59 \\
\hline \multirow[t]{3}{*}{ Evertor moment $(+)$} & $1,3>2$ & $1>2$ & $15-70 \%$ & 1.52 & 0.59 \\
\hline & & $3>2$ & $19-68 \%$ & 2.05 & 0.73 \\
\hline & $2>3$ & $2>3$ & $88-93 \%$ & 0.70 & 0.52 \\
\hline \multirow[t]{2}{*}{ Ex. rotator moment $(-)$} & $2>3$ & $2>3$ & $10-18 \%$ & 1.02 & 0.53 \\
\hline & $1,2>3$ & $1>3$ & $85-94 \%$ & 0.88 & 0.65 \\
\hline \multicolumn{2}{|l|}{ Knee } & $2>3$ & $94-98 \%$ & 0.60 & 0.51 \\
\hline Extensor moment (+) & $2>3$ & $2>3$ & $38-55 \%$ & 6.00 & 0.60 \\
\hline \multirow[t]{2}{*}{ Extensor moment $(+)$} & $1,2>3$ & $1>3$ & $74-88 \%$ & 5.09 & 0.59 \\
\hline & & $2>3$ & $78-84 \%$ & 4.73 & 0.51 \\
\hline \multirow[t]{7}{*}{ Valgus moment $(+)$} & $2,3>1$ & $2>1$ & $1-6 \%$ & 3.12 & 0.77 \\
\hline & & $3>1$ & $2-7 \%$ & 2.79 & 0.57 \\
\hline & $1>2,3$ & $1>2$ & $19-71 \%$ & 5.50 & 0.77 \\
\hline & & $1>3$ & $16-45 \%$ & 6.30 & 0.72 \\
\hline & & $1>3$ & $70-80 \%$ & 2.97 & 0.54 \\
\hline & $1,2>3$ & $1>3$ & $91-100 \%$ & 2.54 & 0.71 \\
\hline & & $2>3$ & $93-100 \%$ & 2.52 & 0.65 \\
\hline \multirow[t]{2}{*}{ Int. rotator moment $(+)$} & $3>1,2$ & $3>1$ & $85-90 \%$ & 0.61 & 0.51 \\
\hline & & $3>2$ & $92-97 \%$ & 0.57 & 0.53 \\
\hline \multicolumn{6}{|l|}{ Hip } \\
\hline \multirow[t]{3}{*}{ Extensor moment $(+)$} & $2>1>3$ & $2<1$ & $30-88 \%$ * & 6.01 & 0.54 \\
\hline & & $2<3$ & $9-94 \%$ * & 12.22 & 0.85 \\
\hline & & $1<3$ & $43-90 \%$ & 8.01 & 0.70 \\
\hline \multirow[t]{2}{*}{ Adductor moment (-) } & $1,2>3$ & $1>3$ & $90-98 \%$ & 3.11 & 0.57 \\
\hline & & $2>3$ & $83-100 \%$ & 3.21 & 0.51 \\
\hline Int. rotator moment $(+)$ & $1>3$ & $1>3$ & $69-75 \%$ & 1.36 & 0.57 \\
\hline
\end{tabular}

\section{Distal joints}

The ankle joint is often not considered when examining hip or knee injuries. However, the ankle joint determines how GRFs travel to proximal joints. The kinematics of the ankle joint differed strongly in all three planes in magnitude and shape. Cluster 1 demonstrated much larger magnitudes in eversion and external rotation and demonstrated medium ankle work in comparison with cluster 2 (least work done) and 3 (largest work done), while all three clusters differ in their ankle flexion angles. This suggests that each of the identified ankle joint strategies induce forces to proximal joints differently.
Relationship between the movement strategy and clinical diagnosis

We expected to see a relationship between cluster type and the specific anatomical diagnosis, which was not the case. If AGP is the result of uncoupling of segmental control in repetitive multidirectional movements, a continuum of musculotendinous and bony overload may be a more appropriate aetiological model. Our belief is that a margin of tolerance exists anatomically and biomechanically for the task execution of propagative movements for a given individual. This margin diminishes with increased training load, genetic anatomical variation, deviation of movement pattern or other extrinsic factors.

Exceeding this margin can lead to subcritical tissue overload -which we propose as a biomechanical overload, the mechanism for AGP development. However, the current study does not examine this assumption, and a prospective study is needed to examine this hypothesis, especially given the finding that there was no relationship between technique and diagnosis.

We contend that the condition AGP is the emergence of a site of tissue failure secondary to biomechanical overload. Once exceeded, either due to training load, technical deficiencies or underlying anatomical abnormality/injury, this presents as a pain at the site of tissue failure. ${ }^{65}$ Coordinated muscle function (strength, power, timing of activation and endurance) is intrinsic to an athlete's ability to control change of direction and produce coordinated movement execution. ${ }^{24} 25$ Changing strength in isolation, in runners, is insufficient to alter movement patterns and coaching intervention using biofeedback, and intrinsic and extrinsic cueing is required. ${ }^{6-68}$ Little work has been done on the changing and coaching of change-of-direction mechanics to date in a rehabilitation setting. The differing movement strategies shown in our cohort strengthens the argument for an approach to rehabilitation, which addresses these deficiencies. Further work is required to assess the features of the rehabilitation before intervention strategies can be developed. However, our research suggests that a 'one-size fits all' approach, focussing on hip strength is unlikely to be effective.

Existing non-surgical rehabilitation programmes mainly target the adductor muscle, due to perceived strength deficit ${ }^{2369} 70$ or the abdominal muscles. In our study, hip adductor moment that is, the force calculated using inverse dynamics exerted to either oppose abduction or produce adduction is predominately, but not exclusively, produced by the adductor muscle complex and was used as a proxy for adductor strength. We did not identify consistent weakness in this measure in any of the clusters as a target for rehabilitation. This was similar in analysis of thorax/ pelvis motion. Although the existence of three distinct clusters suggests possible differentiation of targets for rehabilitation, further work is underway to determine the validity of this approach, rather than the traditional focus on the painful structure.

Biomechanical studies commonly analyse a selected discrete point in combination with a single group design which assumes that (i) differences in overload pattern can be described in a few selected measures (ie, peak moment at peak knee flexion) and (ii) the injury mechanism is homogeneous, respectively. Applying such design may discard important information, and the inherent differences in movement strategies across group members could also act to mask each other's overload mechanism. ${ }^{36}{ }^{37}$ A more advanced way of examining data is the use of continuous and subgroup analysis designs, which has been reported to be superior over a discrete single group design. ${ }^{37}$ 71-74 As such, these techniques were applied in this study. 
ANKLE
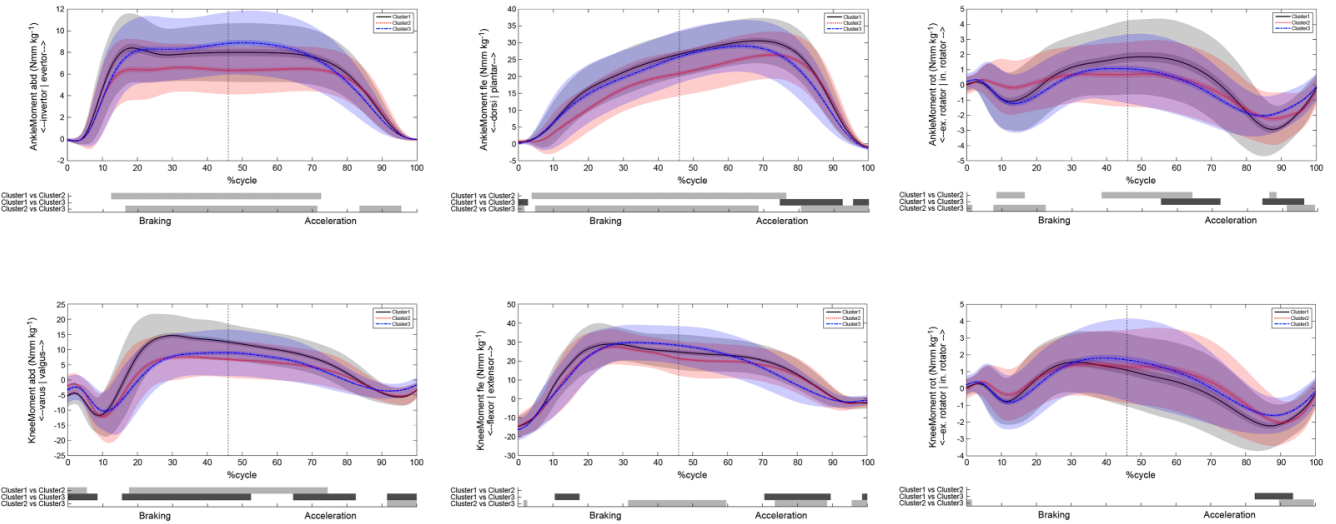

KNEE

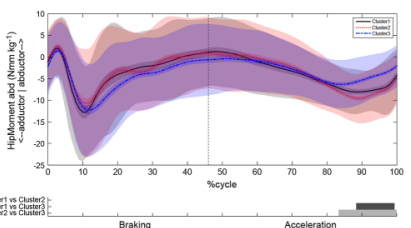

HIP

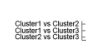
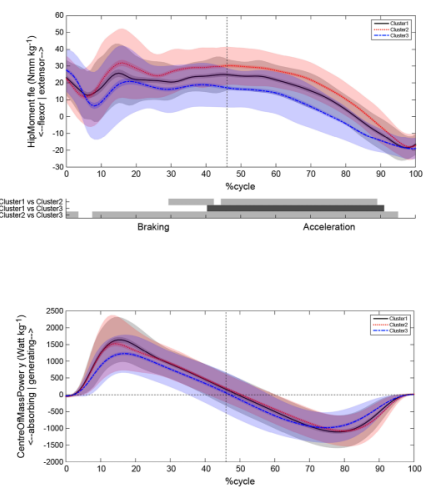

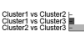

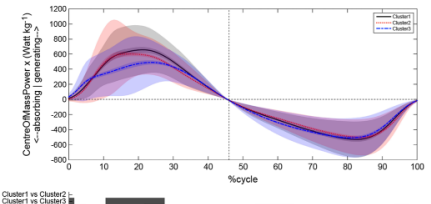

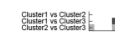
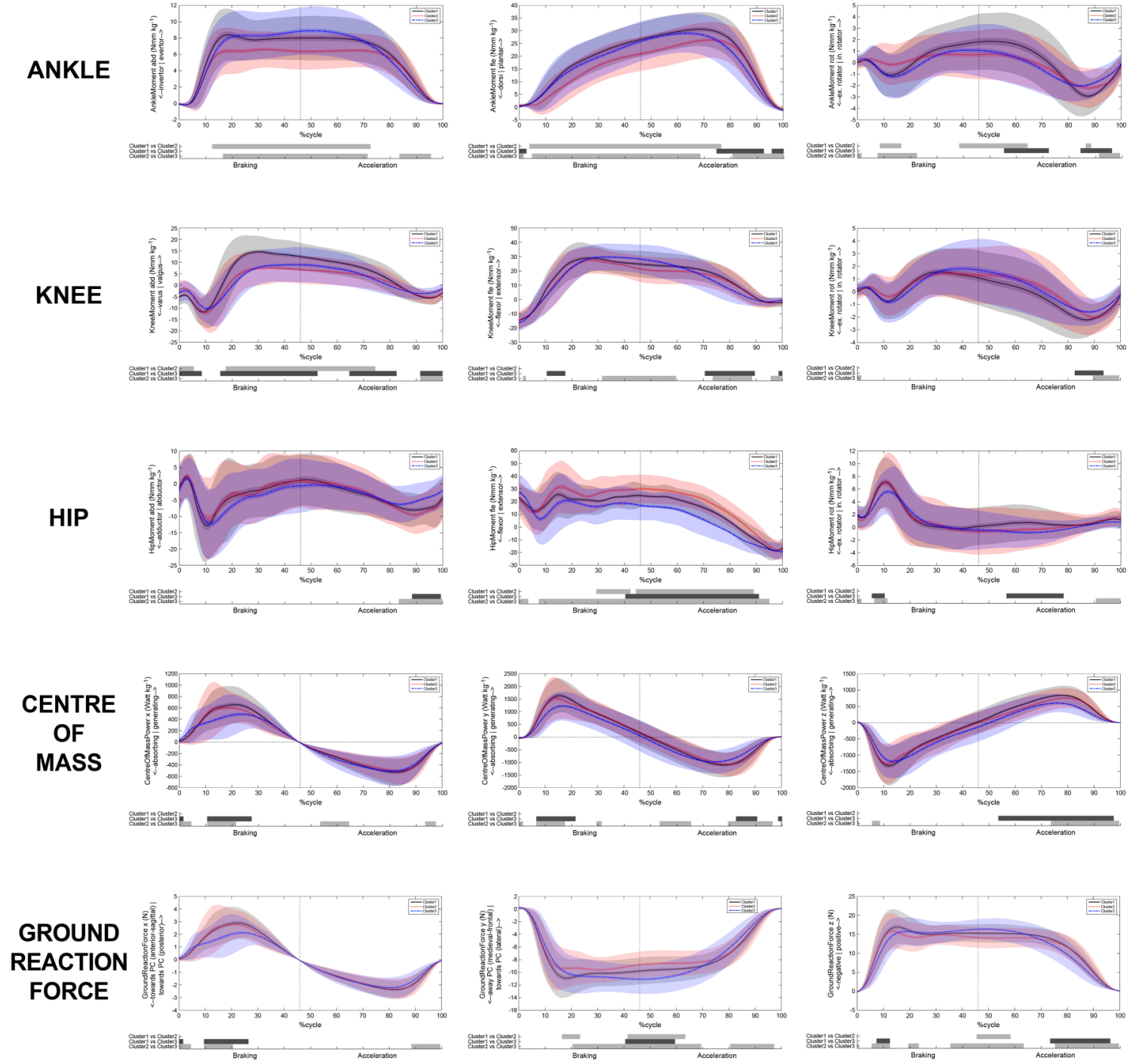

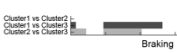
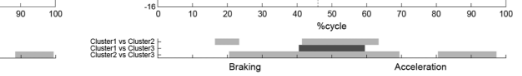

Figure 5 Graphical representations of joint kinetics in each plane, and centre of mass and ground reaction force. Black continuous line represents cluster 1, red dotted line cluster 2 and blue broken line cluster 3. Below each graph, the shaded bars represent significant differences between clusters. Where (A) represents ground reaction force, (B) represents centre of mass, (C) represents ankle, (D) represents knee and (E) represents hip.
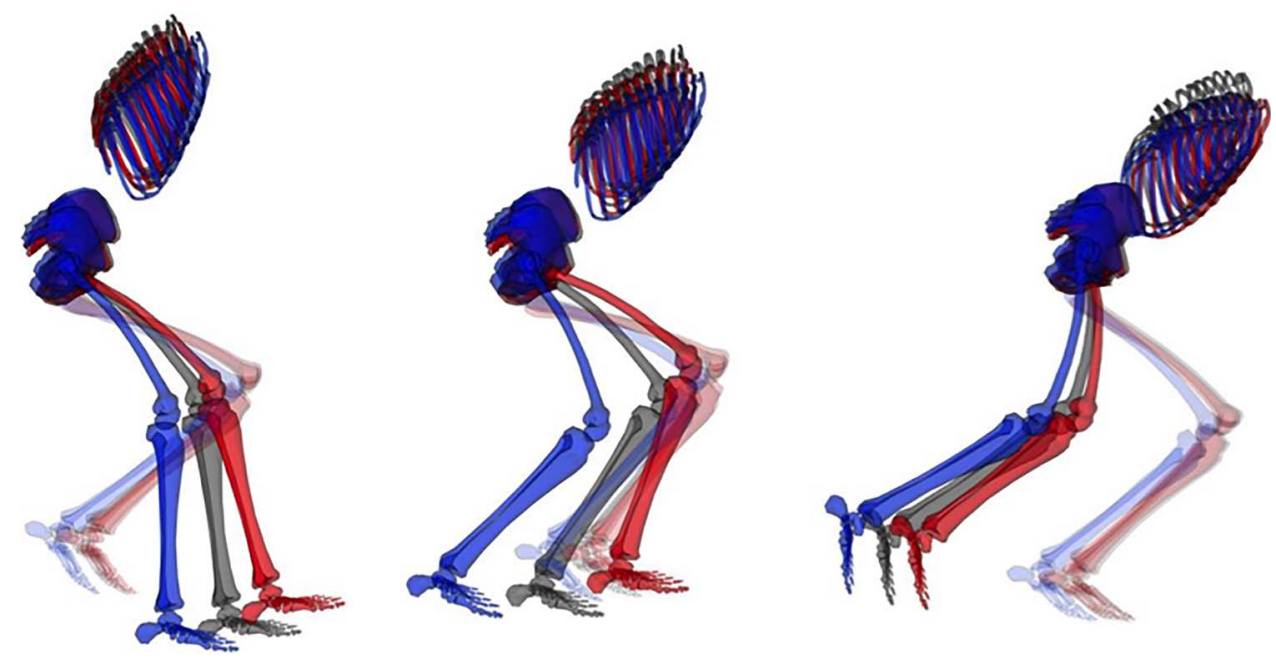

Figure 6 Sagittal view of clusters at impact, 1\% (left); start of acceleration phase, 46\% (middle); and toe-off, 100\% (right). The pelvis of every skeleton has been locked to an $x=0, y=0$ and $z=0$ coordinate, while every rotation angle has been set to 0 . This approach results in the best visualisation in the sagittal plane. The black skeleton represents cluster 1, the red cluster 2 and the blue cluster 3. 

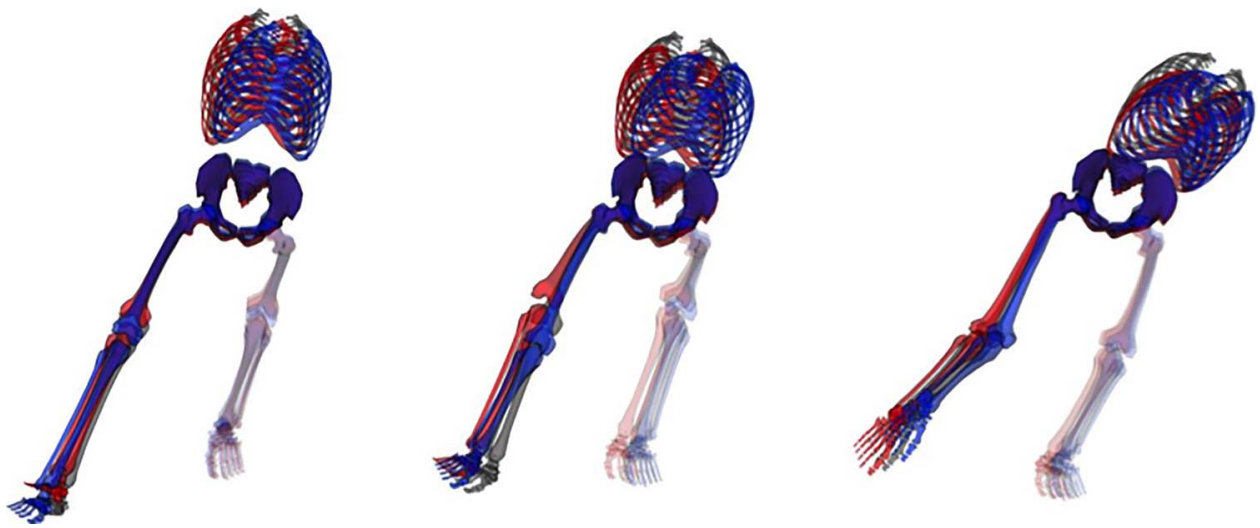

Figure 7 Frontal view of clusters at impact, 1\% (left); start of acceleration phase, 46\% (middle); and toe-off, 100\% (right). The pelvis of every skeleton has been locked to an $\mathrm{x}=0, \mathrm{y}=0$ and $\mathrm{z}=0$ coordinate, while every rotation angle has been set to 0 . This approach results in the best visualisation in the frontal plane. The black skeleton represents cluster 1, the red cluster 2 and the blue cluster 3.
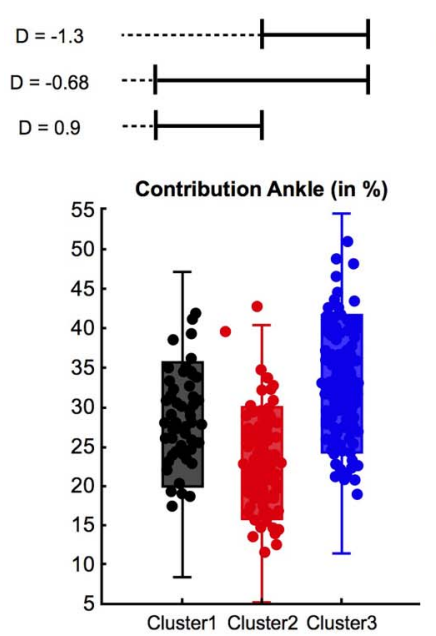
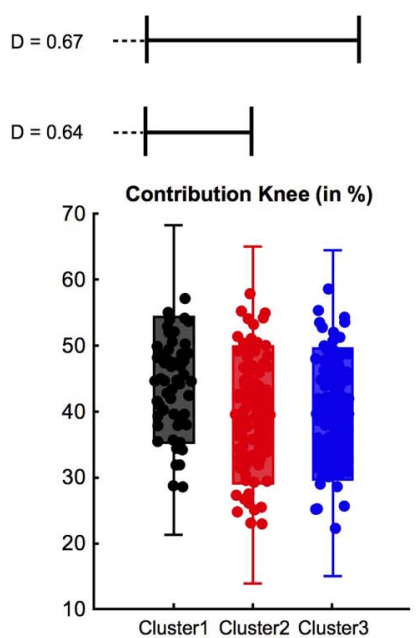
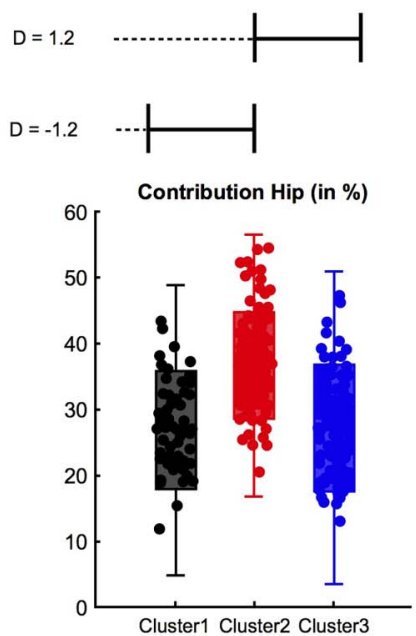

Figure 8 Box plot highlighting differences in work done in cluster 1, 2, 3. D, effect size.

Table 3 Relationship between cluster and anatomical diagnosis $\left(\%{ }^{*}\right)$

\begin{tabular}{|c|c|c|c|c|}
\hline Clinical diagnosis & Cluster1 & Cluster2 & Cluster3 & Total \\
\hline Dx aponeurosis & $\mathrm{n}=76$ (59) & $\mathrm{n}=38(61)$ & $\mathrm{n}=80(61)$ & $\begin{array}{l}n=194 \\
(61 \%)\end{array}$ \\
\hline Dx adductor & $\mathrm{n}=19$ (15) & $\mathrm{n}=10(16)$ & $\mathrm{n}=16(12)$ & $n=45(14 \%)$ \\
\hline $\begin{array}{l}\text { Dx aponeurosis and } \\
\text { Dx hip }\end{array}$ & $\mathrm{n}=5(4)$ & $\mathrm{n}=1(1)$ & $\mathrm{n}=2(2)$ & $\mathrm{n}=8(2 \%)$ \\
\hline Dx hip & $\mathrm{n}=23(18)$ & $\mathrm{n}=10(16)$ & $\mathrm{n}=30(23)$ & $\mathrm{n}=63(20 \%)$ \\
\hline Dx inguinal & $\mathrm{n}=0(0)$ & $\mathrm{n}=1$ (1) & $\mathrm{n}=1$ (1) & $\mathrm{n}=2(1 \%)$ \\
\hline Dx hipflex & $\mathrm{n}=4(3)$ & $\mathrm{n}=1$ (1) & $n=3(2)$ & $\mathrm{n}=8(2 \%)$ \\
\hline $\begin{array}{l}\text { Dx aponeurosis and } \\
\text { Dx adductor }\end{array}$ & $\mathrm{n}=0(0)$ & $\mathrm{n}=1(1)$ & $\mathrm{n}=0(0)$ & $n=1(0 \%)$ \\
\hline $\begin{array}{l}\text { Dx aponeurosis and } \\
\text { Dx hipflex }\end{array}$ & $\mathrm{n}=1(1)$ & $\mathrm{n}=0(0)$ & $\mathrm{n}=0(0)$ & $\mathrm{n}=1(0 \%)$ \\
\hline Total & $\mathrm{n}=128(40 \%)$ & $\mathrm{n}=62(19 \%)$ & $n=132(41 \%)$ & $n=322$ \\
\hline
\end{tabular}

${ }^{*}$ Where $\%$ in parenthesis represents $\%$ of diagnosis within cluster or $\%$ of total number diagnosis.
Our speculation-a possible future

The measurement of movement strategies and quality have been used before in areas such as back pain. ${ }^{75}$ It has also been noted that the site of pain perception often does not correlate with the site or extent of anatomical injury in many areas. ${ }^{76-78}$ Perhaps in our focus on the individual injury sites, we have lost sight of the larger view, and we suggest that, in the future, research into AGP should spend less introspective focus on trying to subclassify into anatomically painful structures ${ }^{15}$ but on the resolution of painful propagative movements in rehabilitation and injury prevention.

Our study does not include a comparison of normative (uninjured) participants. We exclude a comparison with normative data for the current analysis as we were specifically looking at categories within this cohort. AGP could originate from either the inability to execute different movement strategies (eg, continuous overload of a tissue rather than distribution of load over multiple tissues) or the execution of a task using the extreme characteristics of a movement pattern. The question of 'what is an optimal movement' remains. The literature does not satisfy 
the requirements of such an 'optimal' movement in any change-of-direction challenge, although we have demonstrated the performance determinants of this cutting manoeuvre previously in normal participants. ${ }^{31}$ The question remains, however, whether variability within or between clusters is injurious or protective and remains yet to be determined and is the subject of ongoing work.

We tested our participants in a planned maximal effort on clockwise and counter clockwise $110^{\circ}$ change of direction. We acknowledge that strategies employed in an unplanned reactive cut $^{79}$ may be more stressful in neuromuscular $\operatorname{load}^{80}$ and may reveal different strategies. ${ }^{52}$

\section{CONCLUSIONS}

This is the first cohort of patients with AGP in which multiplanar multijoint segmental control was assessed in a change-of-direction manoeuvre. The participants were distributed among three distinct 'clusters' during the biomechanical examination. Anatomical diagnoses were distributed among the three clusters.

\section{What are the findings?}

- Patients with long-standing AGP were grouped into three distinct biomechanical clusters during the performance of a planned $110^{\circ}$ cutting manoeuvre.

- Movement strategies differed in torso, pelvis, hip, knee and ankle joint angle in multiple planes in a cutting manoeuvre.

- Distribution of lower limb joint work was significantly different between each cluster in a planned $110^{\circ}$ cutting manoeuvre.

- There was no correlation seen between anatomical subgrouping/entity and the biomechanical diagnosis.

\section{How might it impact on clinical practice in the future?}

- AGP may be thought of as musculotendinous and bony overload resulting in painful structures without a specific critical injury.

- Considering the three dimensional analysis of movement pattern during a change of direction can give a meaningful addition to a clinical examination.

- The three observed clusters should be explored as targets for rehabilitation to guide return to pain-free play.

- The existing approach, of trying to identify anatomical classification of painful, as opposed to injured structures may give way to whole body focus on movement.

Twitter Follow Enda King @enda_king, Andy Franklyn-Miller @afranklynmiller

Acknowledgements The authors would like to thank Eadaoin Holland, Steven West, Ciara Black, Eamon O'Reilly and Jenny Ward who assisted in the collection of data and the many Sports Surgery Clinic (SSC) staff who contributed to the data processing and all of the participants who agreed to take part in this study.

Contributors AF-M wrote the original draft in conjunction with CR. SG provided specific additional material and writing in the discussion. ECF, EK, SS and KM were integral to study design data collection and interpretation, statistical analysis and editing of the manuscript substantially.
Funding This study was funded by the SSC, and as an industrial partner of INSIGHT, Dublin City University and Science Foundation Ireland (SFI) under grant number SFI/12/RC/2289.

Competing interests None declared.

Ethics approval Sports Surgery Clinic Hospital Ethics Board.

Provenance and peer review Not commissioned; externally peer reviewed.

Open Access This is an Open Access article distributed in accordance with the Creative Commons Attribution Non Commercial (CC BY-NC 4.0) license, which permits others to distribute, remix, adapt, build upon this work non-commercially, and license their derivative works on different terms, provided the original work is properly cited and the use is non-commercial. See: http://creativecommons.org/ licenses/by-nc/4.0/

\section{REFERENCES}

1 Werner J, Hagglund M, Walden $M$, et al. UEFA injury study: a prospective study of hip and groin injuries in professional football over seven consecutive seasons. Br J Sports Med 2009;43:1036-40.

2 Walden $M$, Hagglund $M$, Ekstrand J. The epidemiology of groin injury in senior football: a systematic review of prospective studies. Br J Sports Med. 2015;49:792-7.

3 Brooks JH, Fuller CW, Kemp SP, et al. Epidemiology of injuries in English professional rugby union: part 2 training Injuries. $\mathrm{Br}$ J Sports Med 2005;39:767-75.

4 Brooks JH, Fuller CW, Kemp SP, et al. Epidemiology of injuries in English professional rugby union: part 1 match injuries. Br J Sports Med 2005;39:757-66.

5 Gabbe BJ, Bailey M, Cook JL, et al. The association between hip and groin injuries in the elite junior football years and injuries sustained during elite senior competition. Br J Sports Med 2010;44:799-802.

6 Wilson F, Caffrey S, King E, et al. A 6-month prospective study of injury in Gaelic football. Br J Sports Med 2007;41:317-21.

7 Murphy JC, O'Malley E, Gissane C, et al. Incidence of injury in Gaelic football: a 4-year prospective study. Am J Sports Med 2012;40:2113-20.

8 Bradshaw CJ, Bundy M, Falvey E. The diagnosis of longstanding groin pain: a prospective clinical cohort study. Br J Sports Med 2008;42:851-4.

9 Brukner P, Khan KM. Clinical sports medicine. McGraw Hill, 2012:545.

10 SSC. Examination of the painful athletic groin. Secondary Examination of the painfu athletic groin. 2013. http://www.youtube.com/watch?v=SudZH3FcwMo\&feature= em-share_video_user

11 Zoga AC, Kavanagh EC, Omar IM, et al. Athletic pubalgia and the "sports hernia": MR imaging findings. Radiology 2008;247:797-807.

12 Zoga AC, Mullens FE, Meyers WC. The spectrum of MR imaging in athletic pubalgia. Radiol Clin North Am 2010;48:1179-97.

13 Branci S, Thorborg K, Bech BH, et al. MRI findings in soccer players with long-standing adductor-related groin pain and asymptomatic controls. $\mathrm{Br} J$ Sports Med 2015;49:681-91.

14 Schilders E, Dimitrakopoulou A, Bismil Q, et al. Arthroscopic treatment of labra tears in femoroacetabular impingement: a comparative study of refixation and resection with a minimum two-year follow-up. J Bone Joint Surg $\mathrm{Br}$ 2011;93:1027-32

15 Weir $A$, Brukner $P$, Delahunt $E$, et al. Doha agreement meeting on terminology and definitions in groin pain in athletes. Br J Sports Med 2015;49:768-74.

16 Gilmore 0. Gilmores groin: ten years experience of groin disruption-a previously unsolved problem in sportsmen. Sports Med Soft Tissue Trauma 1991;3:12-14.

17 Brown RA, Mascia A, Kinnear DG, et al. An 18-year review of sports groin injuries in the elite hockey player: clinical presentation, new diagnostic imaging, treatment, and results. Clin J Sport Med 2008;18:221-6.

18 Moeller JL. Sportsman's hernia. Curr Sports Med Rep 2007;6:111-14.

19 Falvey EC, Franklyn-Miller A, McCrory PR. The Groin Triangle: a clinical patho-anatomical approach to the diagnosis of chronic groin pain in athletes. Br J Sports Med 2009;43:213-20.

20 Holmich P. Long-standing groin pain in sportspeople falls into three primary patterns, a "clinical entity" approach: a prospective study of 207 patients. Br J Sports Med 2007;41:247-52.

21 Holmich $\mathrm{P}$, Holmich LR, Bjerg AM. Clinical examination of athletes with groin pain: an intraobserver and interobserver reliability study. Br J Sports Med 2004;38:446-51

22 Thorborg K, Bandholm T, Holmich P. Hip- and knee-strength assessments using a hand-held dynamometer with external belt-fixation are inter-tester reliable. Knee Surg Sports Traumatol Arthrosc 2013;21:550-5.

23 Thorborg K, Bandholm T, Petersen J, et al. Hip abduction strength training in the clinical setting: with or without external loading? Scand J Med Sci Sports 2010;20 (Suppl 2):70-7.

24 Havens KL, Sigward SM. Whole body mechanics differ among running and cutting maneuvers in skilled athletes. Gait Posture 2015;42:240-5. 
25 Havens KL, Sigward SM. Joint and segmental mechanics differ between cutting maneuvers in skilled athletes. Gait Posture 2015;41:33-8.

26 Meeuwisse WH, Tyreman $\mathrm{H}$, Hagel $B$, et al. A dynamic model of etiology in sport injury: the recursive nature of risk and causation. Clin J Sport Med 2007;17:215-19.

27 Wu G, Siegler S, Allard P, et al., Standardization and Terminology Committee of the International Society of Biomechanics. ISB recommendation on definitions of joint coordinate system of various joints for the reporting of human joint motion--part I: ankle, hip, and spine. International Society of Biomechanics. J Biomech 2002;35:543-8.

28 Thorborg K, Holmich P, Christensen R, et al. The Copenhagen Hip and Groin Outcome Score (HAGOS): development and validation according to the COSMIN checklist. Br J Sports Med 2011:45:478-91.

29 Falvey $E$, King $E$, Kinsella $S$, et al. Athletic groin pain (part 1): a prospective anatomical diagnosis of 382 patients--clinical findings, MRI findings and patient-reported outcome measures at baseline. Br J Sports Med 2016;50:423-30.

30 Marshall BM, Franklyn-Miller AD, Moran KA, et al. Can a single-legged squat provide insight into movement control and loading during dynamic sporting actions in athletic groin pain patients? I Sport Rehabil 2015:25:117-25.

31 Marshall BM, Franklyn-Miller AD, King EA, et al. Biomechanical factors associated with time to complete a change of direction cutting maneuver. I Strength Cond Res 2014;28:2845-51.

32 Davis $R$, Ounpuu S, Tyburski D, et al. A Gait analysis data collection and reduction technique. Hum Mov Sci 1991;10:575-87.

33 Kristianslund $E$, Krosshaug $T$, van den Bogert AJ. Effect of low pass filtering on joint moments from inverse dynamics: implications for injury prevention. J Biomech 2012;45:666-71

34 Winter DA. Biomechanics and Motor Control of Human movement. John Wiley and Sons, 2009.

35 Ramsey JO. Functional data analysis. John Wiley and Sons, 2006

36 Richter C, O'Connor NE, Marshall B, et al. Analysis of characterizing phases on waveform: an application to vertical jumps. J App/ Biomech 2014;30:316-21.

37 Richter $\mathrm{C}, \mathrm{O}^{\prime}$ Connor NE, Marshall B, et al. Clustering vertical ground reaction force curves produced during countermovement jumps. J Biomech 2014;47:2385-90.

38 Tibshirani R, Walther G, Hastie T. Estimating the number of clusters in a data set via the gap statistic. J $R$ Stat Soc: Series $B$ (Statistical Methodology) 2001:63:411-23.

39 Pataky TC. RFT1D: Smooth one-dimensional random field upcrossing probabilities in Python. J Stat Software 2016:71:7. doi:10.18637/jss.v071.i07

40 Pataky TC, Vanrenterghem J, Robinson MA. Zero- vs. one-dimensional, parametric vs. non-parametric, and confidence interval vs. hypothesis testing procedures in one-dimensional biomechanical trajectory analysis. J Biomech 2015;48:1277-85.

41 Cohen J. Statistical power analysis for the behavioral sciences. Routledge, 1988.

42 O'Sullivan PB, Phyty GD, Twomey LT, et al. Evaluation of specific stabilizing exercise in the treatment of chronic low back pain with radiologic diagnosis of spondylolysis or spondylolisthesis. Spine (Phila Pa 1976) 1997:22:2959-67.

43 Dostal WF, Soderberg GL, Andrews JG. Actions of hip muscles. Physical therapy 1986;66:351-61.

44 Bergmann $G$, Graichen F, Rohlmann A. Hip joint contact forces during stumbling. Langenbecks Arch Surg 2004:389:53-9.

45 Lewis CL, Sahrmann SA, Moran DW. Effect of hip angle on anterior hip joint force during gait. Gait Posture 2010;32:603-7.

46 Bowman KF Jr, Fox J, Sekiya JK. A clinically relevant review of hip biomechanics. Arthroscopy 2010;26:1118-29.

47 Bian L, Zhai DY, Zhang EC, et al. Dynamic compressive loading enhances cartilage matrix synthesis and distribution and suppresses hypertrophy in hMSC-laden hyaluronic acid hydrogels. Tissue Eng Part A 2012;18:715-24.

48 Robertson BA, Barker PJ, Fahrer M, et al. The anatomy of the pubic region revisited: implications for the pathogenesis and clinical management of chronic groin pain in athletes. Sports Med 2009;39:225-34.

49 Prior $\mathrm{S}$, Mitchell T, Whiteley $\mathrm{R}$, et al. The influence of changes in trunk and pelvic posture during single leg standing on hip and thigh muscle activation in a pain free population. BMC Sports Sci Med Rehabil 2014;6:13.

50 Cashman GE. The effect of weak hip abductors or external rotators on knee valgus kinematics in healthy subjects: a systematic review. J Sport Rehabil 2012;21:273-84

51 Stickler L, Finley M, Gulgin H. Relationship between hip and core strength and frontal plane alignment during a single leg squat. Phys Ther Sport 2015;16:66-71.

52 Houck JR, Duncan A, De Haven KE. Comparison of frontal plane trunk kinematics and hip and knee moments during anticipated and unanticipated walking and side step cutting tasks. Gait Posture 2006;24:314-22.
53 Zajac FE, Gordon ME. Determining muscle's force and action in multi-articular movement. Exerc Sport Sci Rev 1989:17:187-230.

54 Zajac FE. Understanding muscle coordination of the human leg with dynamical simulations. J Biomech 2002:35:1011-18.

55 Blackburn JT, Padua DA. Influence of trunk flexion on hip and knee joint kinematics during a controlled drop landing. Clin Biomech (Bristol, Avon) 2008;23:313-19.

56 Frank B, Bell DR, Norcross MF, et al. Trunk and hip biomechanics influence anterior cruciate loading mechanisms in physically active participants. Am J Sports Med 2013:41:2676-83

57 Nott CR, Zajac FE, Neptune RR, et al. All joint moments significantly contribute to trunk angular acceleration. J Biomech 2010;43:2648-52.

58 Sasaki S, Nagano Y, Kaneko $S$, et al. The relationships between the center of mass position and the trunk, hip, and knee kinematics in the sagittal plane: a pilot study on field-based video analysis for female soccer players. J Hum Kinet 2015:45:71-80.

59 Meyers WC, Greenleaf R, Saad A. Anatomic basis for evaluation of abdominal and groin pain in athletes. Oper Tech Sports Med 2005;13:55-61.

60 Verrall GM, Slavotinek JP, Fon GT. Incidence of pubic bone marrow oedema in Australian rules football players: relation to groin pain. $\mathrm{Br}$ I Sports Med 2001;35:28-33

61 Jardi J, Rodas G, Pedret C, et al. Osteitis pubis: can early return to elite competition be contemplated? Trans/ Med UniSa 2014;10:52-8.

62 Branco RC, da Costa Fontenelle CR, Miranda LM, et al. Comparative study between the pubis of asymptomatic athletes and non-athletes with MRI. Rev Bras Ortop 2010;45:596-600

63 Kuikka L, Hermunen $\mathrm{H}$, Paajanen $\mathrm{H}$, et al. Effect of pubic bone marrow edema on recovery from endoscopic surgery for athletic pubalgia. Scand J Med Sci Sports 2015;25:98-103.

64 Branci S, Thorborg K, Nielsen MB, et al. Radiological findings in symphyseal and adductor-related groin pain in athletes: a critical review of the literature. $\mathrm{Br} J$ Sports Med 2013:47:611-9.

65 Ryan J, DeBurca N, Mc Creesh K. Risk factors for groin/hip injuries in field-based sports: a systematic review. Br J Sports Med 2014:48:1089-96.

66 Herman DC, Onate JA, Weinhold PS, et al. The effects of feedback with and without strength training on lower extremity biomechanics. Am J Sports Med 2009;37:1301-8

67 Noehren B, Scholz J, Davis I. The effect of real-time gait retraining on hip kinematics, pain and function in subjects with patellofemoral pain syndrome. Br J Sports Med 2011:45:691-6.

68 Willy RW, Scholz JP, Davis IS. Mirror gait retraining for the treatment of patellofemoral pain in female runners. Clin Biomech (Bristol, Avon) 2012:27:1045-51.

69 Bandholm T, Thorborg K, Andersson E, et al. Increased external hip-rotation strength relates to reduced dynamic knee control in females: paradox or adaptation? Scand J Med Sci Sports 2011;21:e215-21.

70 Thorborg K, Couppe C, Petersen J, et al. Eccentric hip adduction and abduction strength in elite soccer players and matched controls: a cross-sectional study. Br J Sports Med 2011:45:10-13.

71 Stergiou N, Scott MM. Baseline measures are altered in biomechanical studies. J Biomech 2005:38:175-8.

72 Stergiou N. Innovative analyses of human movement. 1st edn. Leeds, UK: Human KInetics, 2004.

73 Richter C, O'Connor NE, Marshall B, et al. Comparison of discrete-point vs. dimensionality-reduction techniques for describing performance-related aspects of maximal vertical jumping. J Biomech 2014:47:3012-17.

74 Toro B, Nester CJ, Farren PC. Cluster analysis for the extraction of sagittal gait patterns in children with cerebral palsy. Gait Posture 2007:25:157-65.

75 Marras WS, Ferguson SA, Gupta P, et al. The quantification of low back disorder using motion measures. Methodology and validation. Spine 1999:24:2091-100.

76 Grundy PF, Roberts CJ. Does unequal leg length cause back pain? A case-control study. Lancet 1984;2:256-8.

77 Wright AA, Wassinger CA, Frank $M$, et al. Diagnostic accuracy of scapular physical examination tests for shoulder disorders: a systematic review. $\mathrm{Br}$ J Sports Med 2013:47:886-92.

78 Grob D, Frauenfelder H, Mannion AF. The association between cervical spine curvature and neck pain. Eur Spine J 2007:16:669-78.

$79 \mathrm{Kim} \mathrm{JH}$, Lee KK, Kong SJ, et al. Effect of anticipation on lower extremity biomechanics during side- and cross-cutting maneuvers in young soccer players. Am J Sports Med 2014;42:1985-92.

80 Gabbett TJ, Kelly JN, Sheppard JM. Speed, change of direction speed, and reactive agility of rugby league players. J Strength Cond Res 2008;22:174-81. 


\section{Correction: Athletic groin pain (part 2): a prospective cohort study on the biomechanical evaluation of change of direction identifies three clusters of movement patterns}

Franklyn-Miller A, Richter C, King E, et al. Athletic groin pain (part 2): a prospective cohort study on the biomechanical evaluation of change of direction identifies three clusters of movement patterns. Br J Sports Med 2017;51:460-8.

The authors regret that the function used to normalise joint moments to body mass in the analysis for this paper contained an error which resulted in incorrect calculation of these variables. Full re-analysis of the corrected data identified small differences from those originally reported in some phase boundaries for the relevant between-cluster comparisons, but did not affect the participant clustering or the conclusions of the study. Table 2 and Figure 5 should be replaced by the corrected versions below.

Table 2 Descriptive of the kinetic differences between clusters 1, 2 and 3

\begin{tabular}{|c|c|c|c|c|c|}
\hline Measure & Findings & Detailed & Phase & $\begin{array}{l}\text { Mean } \\
\text { difference }\end{array}$ & Effect \\
\hline \multicolumn{6}{|l|}{ Kinetics } \\
\hline \multicolumn{6}{|l|}{ GRF } \\
\hline \multirow[t]{3}{*}{$x$} & $1,2>3$ & $1>3$ & $10 \%-30 \%$ & 0.73 & 0.56 \\
\hline & & $2>3$ & $12 \%-22 \%$ & 0.82 & 0.52 \\
\hline & $3>2$ & $3>2$ & $91 \%-98 \%$ & -0.25 & 0.54 \\
\hline \multirow[t]{3}{*}{ y } & $3>1,2$ & $3>1$ & $43 \%-56 \%$ & 1.29 & 0.54 \\
\hline & & $3>2$ & $31 \%-66 \%$ & 1.87 & 0.77 \\
\hline & $2>3$ & $2>3$ & $84 \%-92 \%$ & -0.99 & 0.53 \\
\hline \multirow[t]{3}{*}{$z$} & $3>2$ & $3>2$ & $38 \%-60 \%$ & -1.98 & 0.68 \\
\hline & $1,2>3$ & $1>3$ & $76 \%-93 \%$ & 1.66 & 0.56 \\
\hline & & $2>3$ & $78 \%-98 \%$ & 1.56 & 0.64 \\
\hline \multicolumn{6}{|l|}{ Ankle } \\
\hline \multirow[t]{4}{*}{ Plantar moment (+) } & $1,3>2$ & $1>2$ & $5 \%-78 \%$ & 0.38 & 0.71 \\
\hline & & $3>2$ & $6 \%-70 \%$ & 0.32 & 0.56 \\
\hline & $1,2>3$ & $1>3$ & $79 \%-93 \%$ & 0.04 & 0.49 \\
\hline & & $2>3$ & $82 \%-100 \%$ & 0.21 & 0.55 \\
\hline \multirow[t]{3}{*}{ Evertor moment (+) } & $1,3>2$ & $1>2$ & $14 \%-74 \%$ & 0.12 & 0.60 \\
\hline & & $3>2$ & $17 \%-73 \%$ & 0.16 & 0.73 \\
\hline & $2>3$ & $2>3$ & $82 \%-96 \%$ & 0.05 & 0.47 \\
\hline \multirow[t]{3}{*}{ Ex. rotator moment $(-)$} & $2>3$ & $2>3$ & $9 \%-23 \%$ & 0.07 & 0.49 \\
\hline & $1>3$ & $1>3$ & $86 \%-97 \%$ & 0.07 & 0.64 \\
\hline & & $2>3$ & $93 \%-100 \%$ & 0.04 & 0.45 \\
\hline \multicolumn{6}{|l|}{ Knee } \\
\hline \multirow[t]{3}{*}{ Extensor moment $(+)$} & $2>3$ & $2>3$ & $32 \%-61 \%$ & 0.45 & 0.59 \\
\hline & $1,2>3$ & $1>3$ & $72 \%-90 \%$ & 0.38 & 0.56 \\
\hline & & $2>3$ & $75 \%-89 \%$ & 0.32 & 0.46 \\
\hline \multirow[t]{7}{*}{ Valgus moment (+) } & $2,3>1$ & $2>1$ & $1 \%-7 \%$ & 0.24 & 0.72 \\
\hline & & $3>1$ & $1 \%-9 \%$ & 0.21 & 0.55 \\
\hline & $1>2,3$ & $1>2$ & $20 \%-75 \%$ & 0.43 & 0.78 \\
\hline & & $1>3$ & $17 \%-53 \%$ & 0.46 & 0.67 \\
\hline & & $1>3$ & $66 \%-83 \%$ & 0.23 & 0.50 \\
\hline & $1,2>3$ & $1>3$ & $93 \%-100 \%$ & 0.16 & 0.72 \\
\hline & & $2>3$ & $93 \%-100 \%$ & 0.14 & 0.60 \\
\hline \multirow[t]{2}{*}{ Int. rotator moment (+) } & $3>1,2$ & $3>1$ & $84 \%-94 \%$ & 0.05 & 0.49 \\
\hline & & $3>2$ & $91 \%-100 \%$ & 0.00 & 0.48 \\
\hline \multicolumn{6}{|l|}{ Hip } \\
\hline \multirow[t]{3}{*}{ Extensor moment $(+)$} & $2>1>3$ & $2<1$ & $31 \%-90 \%$ * & 0.47 & 0.53 \\
\hline & & $2<3$ & $9 \%-96 \%$ & 0.95 & 0.87 \\
\hline & & $1>3$ & $36 \%-92 \%$ & 0.61 & 0.67 \\
\hline \multirow[t]{2}{*}{ Adductor moment (-) } & $1,2>3$ & $1>3$ & $90 \%-100 \%$ & 0.24 & 0.55 \\
\hline & & $2>3$ & $86 \%-100 \%$ & 0.29 & 0.63 \\
\hline Int. rotator moment $(+)$ & $1>3$ & $1>3$ & $57 \%-79 \%$ & 0.10 & 0.57 \\
\hline
\end{tabular}


Text within the results section 'Cluster 3 states Cluster three featured the predominant work done at the ankle with plantarflexor and evertor moments greater in the first part of the cycle but smaller in the latter part 75100\%.' should read 'Cluster three featured the predominant work done at the ankle with plantarflexor and evertor moments greater in the first part of the cycle but smaller in the latter part 79100\%.'

\begin{tabular}{|c|c|c|c|}
\hline ANKLE & $\mathrm{C}_{\ldots}^{\cdots \cdots}$ & 2 & $\underbrace{-1}_{-1+1}$ \\
\hline KNEE & $\frac{1}{-+\ldots}+=$ & $\begin{array}{l}= \\
\\
-\end{array}$ & $\mathrm{C}^{2}$ \\
\hline HIP & Ân: & Somest. & $\mathrm{A}_{-\ldots+\ldots}$ \\
\hline $\begin{array}{l}\text { CENTRE } \\
\text { OF MASS }\end{array}$ & $\left.\right|_{=1} ^{\infty}=$ & $\begin{array}{ll} & \\
& \end{array}$ & W. \\
\hline $\begin{array}{l}\text { GROUND } \\
\text { REACTION } \\
\text { FORCE }\end{array}$ & $\int_{\infty}^{\infty}$ & i) & $\frac{-2 \div=}{15}$ \\
\hline
\end{tabular}

Figure 5 Graphical representations of joint kinetics in each plane, and centre of mass and ground reaction force. Black continuous line represents cluster 1, red dotted line cluster 2 and blue broken line cluster 3. Below each graph, the shaded bars represent significant differences between the clusters.

\section{(2)}

\section{OPEN ACCESS}

Open access This is an open access article distributed in accordance with the Creative Commons Attribution Non Commercial (CC BY-NC 4.0) license, which permits others to distribute, remix, adapt, build upon this work non-

commercially, and license their derivative works on different terms, provided the original work is properly cited, appropriate credit is given, any changes made indicated, and the use is non-commercial. See: http://creativecommons.org/licenses/by-nc/ 4.0\%.

C Author(s) (or their employer(s)) 2020. Re-use permitted under CC BY-NC. No commercial re-use. See rights and permissions. Published by BMJ.

Br J Sports Med 2020;54:e5. doi:10.1136/bjsports-2016-096050corr1

D Check for updates 